\title{
Ameloblastic Carcinoma
}

National Cancer Institute

\section{Source}

National Cancer Institute. Ameloblastic Carcinoma. NCI Thesaurus. Code C7492.

A rare, cytologically malignant ameloblastoma that may metastasize. 